ORIGINAL ARTICLE

\title{
Frequency of Vitamin D deficiency in liver cirrhosis and its correlation with Child Pugh Score
}

\author{
M. AKIF DILSHAD ${ }^{1}$, SHAFQAT RASOOL ${ }^{2}$, AMIR LATIF ${ }^{3}$, ASIF GUL ${ }^{4}$, ISRAR UL HAQUE ${ }^{5}$, GHIAS UN NABI TAYYAB ${ }^{6}$ \\ ${ }^{1}$ Associate Professor Gastroenterology, AMC / PGMI / Lahore General Hospital, Lahore \\ ${ }^{2}$ Assistant Professor Gastroenterology, AMC / PGMI / Lahore General Hospital, Lahore \\ ${ }^{3}$ Associate Professor HPB and Liver Transplant, Shaikh Zayed Medical Complex, Lahore \\ ${ }^{4}$ Associate Professor Gastroenterology, NMC, Nishtar Hospital, Multan \\ ${ }^{5}$ Associate Professor Medicine, AMC / PGMI / Lahore General Hospital, Lahore \\ ${ }^{6}$ Professor Medicine / Gastroenterology, AMC / PGMI / Lahore General Hospital, Lahore \\ Correspondence to: Dr. M. Akif Dilshad, Email: kfdilshad@yahoo.com, Cell: 03214340133
}

\begin{abstract}
Objective: To determine the frequency of vitamin $D$ deficiency in patients with liver cirrhosis and the relationship of vitamin $D$ deficiency with Child Pugh Class in patients with cirrhosis.

Materials and Methods: Vitamin D and calcium levels were checked in patients with cirrhosis of liver aged 18 to 80 years admitted in Gastroenterology department of Lahore General Hospital. Investigations were also done to calculate Child Pugh (CTP) score and Child Class was assigned on the basis of score. Quantitative variables were expressed in terms of mean and standard deviation. Frequency and percentage were used for qualitative measures. The $p$-value was calculated by the contingency coefficient to find a relationship of vitamin $D$ levels to CTP scores of liver cirrhosis. Data was analyzed using SPSS 24

Study Duration: The study was carried out from December 2019 to October 2020

Results: A total of 170 patients with mean age of $43.82 \pm 9.72(19-61)$ years were evaluated of which 144 (84.7\%) were males, 26 (15.3\%) were females. Vitamin D3 deficiency was found in 144/170 (84.7\%) patients while insufficiency was found in $14 / 170(8.2 \%)$. It was more common in male patients $(86.1 \%)$ compared to female patients (76.9\%). Mean vitamin D3 levels was $14.4 \pm 9.4 \mathrm{ng} / \mathrm{ml}$. Patients with Child A cirrhosis 6/10 (60\%) had deficiency, with child B 66/82 (80.5\%) while with Child C 72/78 (92.3\%) had deficiency of Vitamin D3.

Conclusion: Vitamin D deficiency is common in patients with cirrhosis and level has decreased stepwise with higher Child Pugh Class.

Keywords: Cirrhosis, Vitamin D, Child Pugh score
\end{abstract}

\section{INTRODUCTION}

Hepatitis $B$ and $C$ are the leading cause of cirrhosis in Asia. Cirrhosis of liver is related to many metabolic disorders in the body. It directly or in directly affects the calcium, phosphate and vitamin D metabolism thus affecting the musculoskeletal system termed as hepatic osteodystrophy, resulting in increased tendency of fractures ${ }^{(1,2)}$

Vitamin D has two forms, vitamin D2 (ergocalceferol) is obtained from plant source while vitamin D3 (cholecalciferol) is obtained from sunlight and animal sources. Both these forms undergo hydroxylation in liver at 25 site followed by hydroxylation at 1 site in kidneys to form the biologically active 1,25 hydroxy vitamin D. This biologically active vitamin $\mathrm{D}$ maintains the serum calcium levels by increasing the absorption in the duodenum and acting on osteoblast and osteoclast to mobilize the calcium. The biologically active vitamin $\mathrm{D}$ is regulated by parathyroid levels, calcium, phosphate levels and osteoclast activity ${ }^{(3)}$

Classically the vitamin D deficiency is associated with rickets in children and Osteomalacia in adults and there is evidence now to the wider benefits of vitamin D sufficiency in skeletal and non-skeletal disorders including low mortality ${ }^{(5)}$, lower risk of diabetes ${ }^{(6)}$ and infection ${ }^{(7)}$

Vitamin D deficiency in liver disease is common as the 25 hydroxylation of vitamin $D$ is carried out in liver, moreover the decrease in appetite, reduced physical activity and decease absorption of fat soluble vitamin also contribute to it. Vitamin D deficiency has been reported in liver disease and lower levels has been reported in advance liver disease ${ }^{(8)}$. Studies have also shown low levels of vitamin $D$ in NAFLD patients suggesting that vitamin $\mathrm{D}$ might have a role in developing cirrhosis due to $\operatorname{NAFLD}^{(9)}$

\section{MATERIAL AND METHOD}

All Patients with cirrhosis of liver aged 18 to 80 years admitted during December 2019 to October 2020 in Gastroenterology department of Lahore General Hospital were included. Cirrhosis was labelled based on ultrasound abdomen (Coarse texture and irregular liver borders), AST to platelet ratio index (APRI score) more than 2 or medical record suggesting decompensated cirrhosis i.e. history of ascites, variceal bleeding or hepatic encephalopathy.

Patients were excluded from study if they were on calcium, vitamin $\mathrm{D}$ or bisphosphonates therapy, have chronic kidney disease, HCC or any other malignancy.

Informed consent was taken, detailed history and examination was performed. Blood samples were taken for Complete blood counts, Liver function tests with Albumin, Prothrombin time (PT)/ International normalization ratio (INR), Renal function tests (RFTS), Serum Electrolytes(Including Calcium), 25 Hydroxy Vitamin D3 levels, Viral marker for Hepatitis B and C. Ultrasound abdomen was also done. Patients were categorized into class A, B or C on the basis of child Pugh score. Vitamin D3 deficiency was defined as levels $<20 \mathrm{ng} / \mathrm{ml}$, Insufficiency was defined as levels 21 to $30 \mathrm{ng} / \mathrm{ml}$ while levels more than $30 \mathrm{ng} / \mathrm{ml}$ was labelled as normal.

Quantitative variables were expressed in terms of mean and standard deviation. 
Frequency and percentage were used for qualitative measures. The $p$-value was calculated by the contingency coefficient to find a relationship of vitamin $D$ levels to $C P$ scores of liver cirrhosis and also with other variables. Data was analyzed using SPSS 24

\section{RESULTS}

A total of 170 patients with mean age of $43.82 \pm 9.72$ (19$61)$ years were evaluated. 144 (84.7\%) were males, 26 (15.3\%) were females with mean weight of $69.8 \pm 11.8$ (4897) Kgs.10/170(5.9\%) were Child Pugh Class A, $82 / 170(48.2 \%)$ were class B and $78 / 170(45.9 \%)$ were class C (Figure1).

Vitamin D3 deficiency was found in 144/170 (84.7\%) patients while insufficiency was found in 14/170(8.2\%). $124 / 144(86.1 \%)$ males had Vitamin D3 deficiency while 20/26 (76.9\%) female had vitamin D3 deficiency. $10 / 144(6.9 \%)$ males while $4 / 26(15.4 \%)$ females had vitamin D3 insufficiency.

Hypocalcemia (after correcting for low Albumin) was found in $28 / 170(16.5 \%)$ of the patients. $22 / 144(15.3 \%)$ males had hypocalcemia while 6/26 (23.1\%) female had hypocalcemia. Overall Mean calcium (corrected for low Albumin) levels was $9.2 \pm 0.57$ (7.7-10.6) $\mathrm{mg} / \mathrm{dl}, \quad 9.4 \pm 0.78$ ( 8.3-10.5) $\mathrm{ng} / \mathrm{ml}$ in Child A cirrhosis, $9.1 \pm 0.52$ ( 7.9-10.3) $\mathrm{mg} / \mathrm{dl}$ in Child $B$ cirrhosis while in Child $C$ cirrhosis mean calcium levels was $9.2 \pm 0.59$ (7.7-10.6) $\mathrm{mg} / \mathrm{dl}$

Patients with Child A cirrhosis 6/10 (60\%) had deficiency, with child B 66/82 (80.5\%) while with Child C $72 / 78(92.3 \%)$ had deficiency of Vitamin D3.While Patients with Child A cirrhosis 2/10 (20\%) had insufficiency, with child B 10/82(12.2\%) while with Child C 2/78 (2.6\%) had insufficiency of Vitamin D3 (Figure2).

Overall Mean vitamin D3 levels was $14.4 \pm 9.4 \mathrm{ng} /$ $(4.2-60.4) \mathrm{ml}$, in patients with Child A cirrhosis mean Vitamin D 3 levels was $19.3 \pm 10.6$ (11-37) ng/ml, while in Child B cirrhosis mean Vitamin D 3 levels was $15.3 \pm 10.9$ ( 4.2-60.4) $\mathrm{ng} / \mathrm{ml}$, while in Child $\mathrm{C}$ cirrhosis mean Vitamin D 3 levels was $12.9 \pm 7.2(5.3-39.7) \mathrm{ng} / \mathrm{ml}$.

Figure 1:

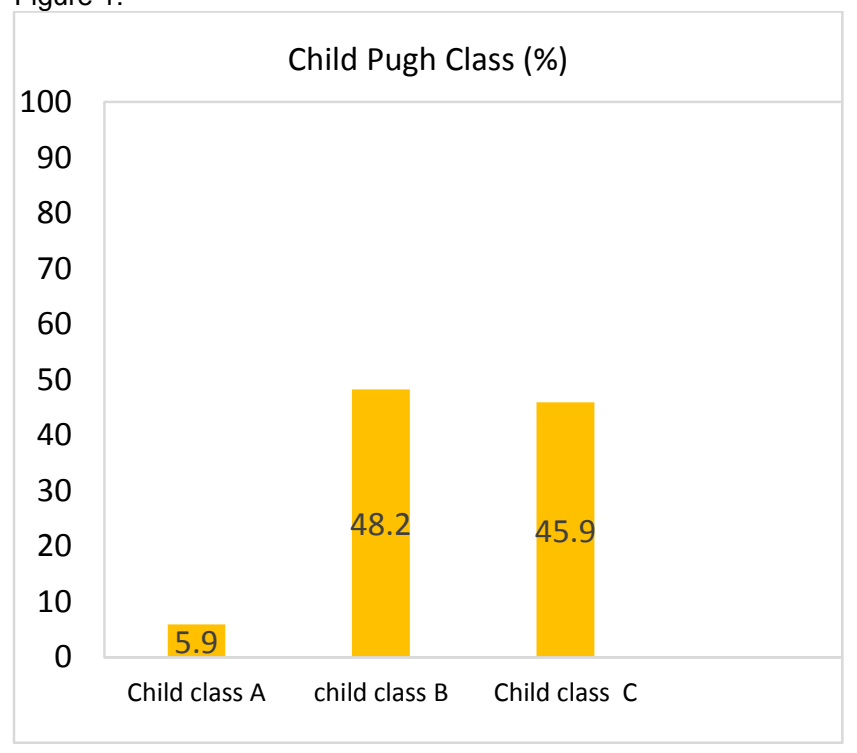

Figure 2:

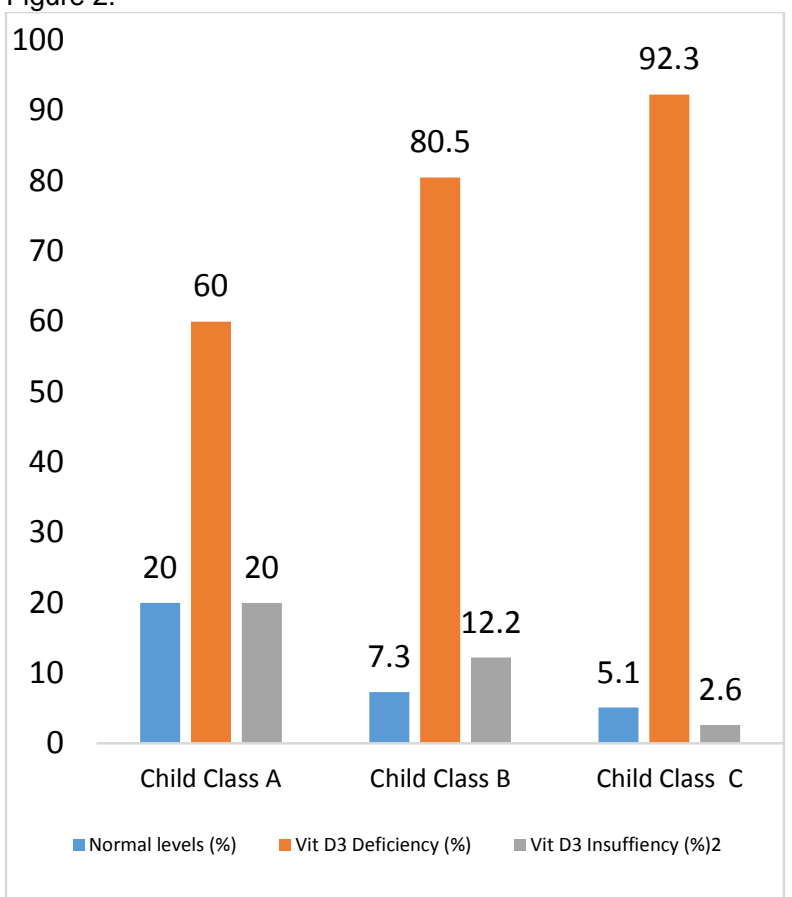

\section{DISCUSSION}

Vitamin D deficiency $(<20 \mathrm{ng} / \mathrm{ml})$ is quite common world over with estimated prevalence of $24 \%$ in US ${ }^{(10)}, 37 \%$ in Canada (11)and $40 \%$ in Europe (12) while severe deficiency $(<12 \mathrm{ng} / \mathrm{dl})$ is less common, however in India, Pakistan and Afghanistan severe deficiency is reported to be $>20 \%$ of the population (13)

Certain group of patients including chronic kidney disease, chronic liver disease and post renal and liver transplant may have much higher prevalence of vitamin $D$ deficiency ranging from 85 to $99 \%(14,15,16)$. In our study Vitamin D deficiency was found in 144/170 (84.7\%) patients while insufficiency was found in 14/170(8.2 \%). A study published from Spain also found that vitamin $D$ level either deficient or insufficient in $87 \%$ of the liver disease patients, with an average concentration of $18.8 \mathrm{ng} / \mathrm{ml}{ }^{(8)}$. While the overall mean vitamin $D$ level in our study was $14.4 \pm 9.4 \mathrm{ng} / \mathrm{ml}$. Vitamin D deficiency was initially thought to be more common in cholestatic disorders but evidence is growing that deficiency is present in other causes of chronic liver disease as reported in a study of patients with hepatitis $C^{(17)}$

Hypocalcemia was noted in $16.5 \%$ of patients in our study however Kumar et al reported patients with chronic liver disease having normal calcium level in their study (18). This could be related to calcium supplementation that usually liver patients are on.

In current study 124/144 (86.1\%) males had Vitamin D3 deficiency while $20 / 26$ (76.9\%) female had vitamin D3 deficiency. 10/144(6.9 \%) males while 4/26(15.4\%) females had vitamin D3 insufficiency. Similar gender distribution was previously reported in the literature in multiple studies $(19,20)$ however vitamin D deficiency was reported to be more common in females in a study conducted in Iraq ${ }^{(21)}$ 
Inverse relationship between severity of liver disease and vitamin D levels was reported as $55.2 \%$ of decompensated cirrhosis patients were Vitamin-D deficient compared to $13.6 \%$ in compensated cirrhosis by Falak etal (22)

In this study we found that in patients with liver cirrhosis vitamin D has inverse relationship with Child Pugh class as deficiency is more common as the Child class progresses. Patients with Child A cirrhosis 6/10 (60\%) had deficiency, with child B 66/82 (80.5\%) while with Child C $72 / 78(92.3 \%)$ had deficiency of Vitamin D3. Low vitamin D levels were reported and its inverse relationship with Child Pugh class and MELD score in chronic liver disease patients was also demonstrated in a study by Zubia etal (23) Similar results were shown by a Chinese study that vitamin D level decreased stepwise with higher Child Pugh class (24). Farnendez et al in his study also demonstrated inverse relation between Child class and Vitamin D levels ${ }^{(8)}$

\section{CONCLUSION}

Vitamin $D$ deficiency is common in patients with cirrhosis and level has decreased stepwise with higher Child Pugh Class.

Limitation of the study: The impact of vitamin D replacement was not recorded during the study

\section{REFERENCES}

1. Malham $M$, Jørgensen SP, Ott $P$, Agnholt J, Vilstrup $H$, Borre $\mathrm{M}$ et al. Vitamin $\mathrm{D}$ deficiency in cirrhosis relates to liver dysfunction rather than aetiology. World journal of gastroenterology: WJG. 2011 Feb 21;17(7):922.

2. Gatta A, Verardo A, Di Pascoli M, Giannini S, Bolognesi M. Hepatic osteodystrophy. Clinical Cases in Mineral and Bone Metabolism. 2014 Sep;11(3):185.

3. Shubair ME, Abo Shamala H, Sirdah M. Parathyroid Hormone, Calcium and Phosphorus Levels in Hemodialysis Patients at Al-Shifa Hospital, Gaza-Palestine. IUG Journal for Natural and Engineering Studies. 2014;22(1)

4. Bischoff-Ferrari HA, Kiel DP, Dawson-Hughes B, Orav JE, Li R, Spiegelman D, Dietrich T, Willett WC. Dietary calcium and serum 25-hydroxyvitamin D status in relation to BMD among US adults. Journal of Bone and Mineral Research. 2009 May;24(5):935-42.

5. Fan X, Wang J, Song M, Giovannucci EL, Ma H, Jin G, Hu $Z$, Shen $H$, Hang D. Vitamin D status and risk of all-cause and cause-specific mortality in a large cohort: results from the UK Biobank. The Journal of Clinical Endocrinology \& Metabolism. 2020 Oct;105(10):e3606-19.

6. Berridge MJ. Vitamin D deficiency and diabetes. Biochemical Journal. 2017 Apr 15;474(8):1321-32.

7. Grant WB, Baggerly CA, Lahore H. Reply:"Vitamin D supplementation in influenza and COVID-19 infections. Comment on: Evidence that vitamin $\mathrm{D}$ supplementation could reduce risk of influenza and COVID-19 infections and deaths nutrients 2020, 12 (4), 988”. Nutrients. 2020 Jun;12(6):1620.

8. Fernández NF, Torres PL, Matias DJ, Plaza FJ, Goñi JL. Vitamin $D$ deficiency in chronic liver disease, clinicalepidemiological analysis and report after vitamin $d$ supplementation. Gastroenterología y Hepatología (English Edition). 2016 May 1;39(5):305-10.

9. Gad Al, Elmedames MR, Abdelhai AR, Marei AM. The association between vitamin $D$ status and non-alcoholic fatty liver disease in adults: a hospital-based study. Egyptian Liver Journal. 2020 Dec;10(1):1-8.
10. Schleicher RL, Sternberg MR, Looker AC, Yetley EA, Lacher DA, Sempos CT, et al. National estimates of serum total 25Hydroxyvitamin D and metabolite concentrations measured by liquid chromatography-Tandem mass spectrometry in the US population during 2007-2010. J Nutr. 2016;146:105161.

11. Sarafin K, Durazo-Arvizu R, Tian L, Phinney KW, Tai S, Camara JE, et al. Standardizing 25-hydroxyvitamin D values from the Canadian Health Measures Survey. Am J Clin Nutr. 2015;102:1044-50.

12. Cashman KD, Dowling KG, Škrabáková Z, Gonzalez-Gross $M$, Valtueña J, De Henauw S, et al. Vitamin D deficiency in Europe: pandemic? Am J Clin Nutr. 2016;103:1033-44.

13. Cashman KD. Vitamin D deficiency: defining, prevalence, causes, and strategies of addressing. Calcified tissue international. 2020 Jan 1:1-6.

14. Courbebaisse M, Alberti C, Colas S, Prie D, Souberbielle JC, Treluyer JM. et al. Vitamin D supplementation in renAL transplant recipients (VITALE): a prospective, multicentre, double-blind, randomized trial of vitamin $D$ estimating the benefit and safety of vitamin D3 treatment at a dose of $100,000 \mathrm{UI}$ compared with a dose of $12,000 \mathrm{UI}$ in renal transplant recipients: study protocol for a double-blind, randomized, controlled trial. Trials. 2014;15:430.

15. Vos R, Ruttens D, Verleden SE, Vandermeulen E, Bellon H, Van Herck A, et al. High-dose vitamin D after lung transplantation: a randomized trial. J Heart Lung Transplant. 2017;36:897-905.

16. Zhou Q, Li L, Chen Y, Zhang J, Zhong L, Peng Z, et al. Vitamin $D$ supplementation could reduce the risk of acute cellular rejection and infection in vitamin D deficient liver allograft recipients. Int Immunopharmacol. 2019;75:105811

17. Petta $S$, Cammà $C$, Scazzone $C$, Tripodo $C$, Di Marco V, Bono A, Cabibi D, Licata G, Porcasi R, Marchesini G, Craxí A. Low vitamin $D$ serum level is related to severe fibrosis and low responsiveness to interferon-based therapy in genotype 1 chronic hepatitis C. Hepatology. 2010 Apr;51(4):1158-67.

18. Kumar R, Kumar P, Saxena KN, Mishra M, Mishra VK, Kumari $A$, et al. Vitamin $D$ status in patients with cirrhosis of the liver and their relatives-A case control study from North India. Indian J Gastroenterol 2017;36:50-55.

19. AIQuaiz AM, Kazi A, Fouda M, Alyousefi N. Age and gender differences in the prevalence and correlates of vitamin $D$ deficiency. Archives of osteoporosis. 2018 Dec;13(1):1-1.

20. Sanghera DK, Sapkota BR, Aston CE, Blackett PR. Vitamin $\mathrm{D}$ status, gender differences, and cardiometabolic health disparities. Annals of Nutrition and Metabolism. 2017;70(2):79-87.

21. Al-Horani H, Abu Dayyih W, Mallah E, Hamad M, Mima M, Awad R, Arafat T. Nationality, gender, age, and body mass index influences on vitamin $D$ concentration among elderly patients and young Iraqi and Jordanian in Jordan. Biochemistry research international. 2016 Oct;2016.

22. Falak S, Aftab L, Saeed M, Islam A. Prevalence of Vitamin-D deficiency is related to severity of liver damage in HepatitisC patients. Pakistan journal of medical sciences. 2020 Mar;36(3):445.

23. Jamil Z, Arif S, Khan A, Durrani AA, Yaqoob N. Vitamin D deficiency and its relationship with Child-Pugh class in patients with chronic liver disease. Journal of clinical and translational hepatology. 2018 Jun 28;6(2):135.

24. Zhao XY, Li J, Wang JH, Habib S, Wei W, Sun SJ. Vitamin D serum level is associated with Child-Pugh score and metabolic enzyme imbalances, but not viral load in chronic hepatitis B patients. Medicine (Baltimore) 2016;95:e3926 